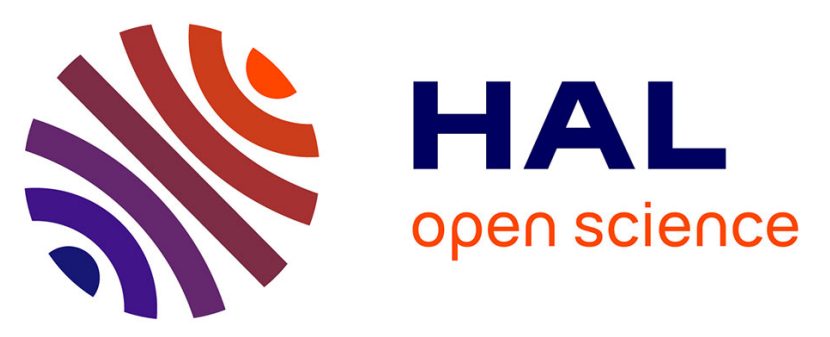

\title{
Exploring the potential of local market in remunerating water ecosystem services in Cambodia: An application for endogenous attribute non-attendance modelling
} Tina Rambonilaza, Malyne Neang

\section{- To cite this version:}

Tina Rambonilaza, Malyne Neang. Exploring the potential of local market in remunerating water ecosystem services in Cambodia: An application for endogenous attribute non-attendance modelling. Water Resources and Economics, 2019, 25 (January), pp.14-26. 10.1016/j.wre.2018.07.001 . hal02608817

\section{HAL Id: hal-02608817 \\ https: / hal.inrae.fr/hal-02608817}

Submitted on 21 Oct 2021

HAL is a multi-disciplinary open access archive for the deposit and dissemination of scientific research documents, whether they are published or not. The documents may come from teaching and research institutions in France or abroad, or from public or private research centers.
L'archive ouverte pluridisciplinaire HAL, est destinée au dépôt et à la diffusion de documents scientifiques de niveau recherche, publiés ou non, émanant des établissements d'enseignement et de recherche français ou étrangers, des laboratoires publics ou privés.

\section{(ㄷ)(1) $\$$}

Distributed under a Creative Commons Attribution - NonCommerciall 4.0 International 
Exploring the potential of local market in remunerating water ecosystem services in Cambodia: an application for endogenous attribute non-attendance modelling

Tina RAMBONILAZA (corresponding author)

Irstea, UR ETBX, F - 33612 Cestas, France

50 avenue de Verdun, 33612 Cestas. France

Phone : 33 (0)5 57890837

tina.rambonilaza@irstea.fr

\section{Malyne NEANG}

Faculty of Agricultural Economic and Rural development, Royal University of Cambodia

Dangkor district, Phnom Penh, Cambodia, P.O Box 2696

Phone: (855) 0772201 47/ 070607062

E-mail: nmalyne@gmail.com 


\title{
Exploring the potential of local market in remunerating water ecosystem services as rice attributes: an application for endogenous attribute non attendance
}

\begin{abstract}
Within South East Asia, certification and local market development may play an important role in incentivizing farmers to continue with nature-based solutions delivered by organic or traditional farming practices and avoid using environmentally detrimental production techniques. The purpose of this study is to use economic valuation in order to achieve an empirical understanding of local consumer preferences for different attributes of rice products. Application of the agrarian system approach reveals that rice cultivation systems observed in the Tonle Sape Lake of the Mekong River Basin in Cambodia (our study case) may target three ecosystem services that present the characteristics of public goods and may benefit consumer support. A choice experiment survey was administered among local consumers in the city of Phnom Penh in 2013. Econometric analysis indicates high rate of non-attendance for the price attribute. It also suggests that $17 \%$ of the respondents made their choices neglecting attributes describing ecosystem services. However, there are evidence of consumers' willingness to pay (WTP) for certified organic rice higher than the price-premium observed on the local market. Furthermore, there is additional WTP value for the preservation of ecosystem services. We discuss the implications of our findings on potential payment for ecosystem services in the specific case of rice.
\end{abstract}

\section{Introduction}

For many countries in Southeast Asia, implementation of new varieties, high application of synthetic fertilizers and pesticides to boost agricultural productivity [1], remain a major feature of agricultural practices aimed at ensuring future food security for local populations and helping farmers work their way out of poverty [2, 3]. However, for many regions, intensive farming practices have implications for the structure and functions of ecosystems which may alter the resilience of agro-ecosystems and the well-being of poor farmers who rely more directly on ecosystem functions and services [4]. This is notably the case for rice production in Cambodia. The country was not part of the green revolution initiated in the 1960 's by other countries, and maintained its own traditional practices of agriculture until 
joining the ASEAN free trade area in 1999. To satisfy national export targets, the agricultural sector is oriented towards an intensive model, involving chemical inputs, irrigation and only 10 selected high-yield varieties of rice. Given that the majority of Cambodia's rice is grown within the floodplain of Tonle Sap Lake $[5,6]$ these practices pose a risk to water quality. Agro-chemical residues threaten food security and public health, as a large part of the urban and rural population rely on rice-field species (rats and snails; insects; frogs; snakes) as well as a lot of other inland aquatic species as important sources of proteins $[7,8]$.

A large body of the literature argues that developing organic farming labelling could be a solution to resolving environmental problems in agro-ecosystems, thus improving the livelihood of rural people and helping to meet the demand for safe food for consumers $[9,10]$. Traditional agricultural practices are also "organic by default" or "near-organic" as they do not use chemical inputs, or do so in very low quantities. They are still in rural areas, and contribute to the preservation of human and environmental health. Thus, export orientated organic farming has been advocated to suit traditional practices as the additional cost for compliance with the international standard was assumed to be low. However, poor farmers were still excluded from the global food supply-chain for a range of reasons [11]. In recent years, standards development for locally oriented organic production systems has become one of the main policy objectives for governments, NGOs, and farmers' organizations, due to the potential they represent for smallholder farmers through access to a higher value agricultural market [12].

Building on this point, another strand of literature focuses on the implementation of the popular payment for ecosystem services (PES) scheme, as a pragmatic approach to remunerating low-income farmers for maintaining the ecological benefits of traditional cropping practices [13]. The specific characteristics of ecosystem services (i.e. pure public goods or pooled common resources) would appear to call for some kind of government-driven initiative. However, given the small proportion of public funds allocated to conservation programs in the developing world, PES schemes based on market arrangements between farmers and consumers also need to be considered $[14,15]$. This will aid in integrating public goods such as aquatic biodiversity in consumers' purchasing decisions.

Targeting the local urban market, as the first market for "ecosystem services" (ESs) remains a major policy challenge in developing countries. A large proportion of local consumers are too 
poor to pay the price premium for certified products [16]. Furthermore, the motivation of consumers to purchase organic foods in Asian countries such as in Thailand, Malaysia and Vietnam derives from quality nutrition and health $[17,18]$. The potential for local consumers to pay for ecosystem services has not yet been examined by either the empirical literature or current certification policies so far. Empirical research that addresses the extent to which specific ecosystem services delivered by rice cropping systems may influence preferences and shopping behavior of local urban consumers is absent from the literature. This study addresses this research gap by investigating, urban consumers' preferences for rice attributes in Cambodia with choice experiment method.

Identifying ecosystem services to present to the consumer, is therefore an essential step in achieving better market prices for those who produce their rice through traditional means. The ecosystem services provided by rice cropping systems have only recently begun to attract the attention of researchers [19]. These authors developed an expert-based screening of ecosystem services for irrigated rice cropping systems in Vietnam and the Philippines. Our study adopts another pragmatic approach based on the French agrarian system approach [20]. We developed a detailed analysis of rice cropping systems observed for Tonle Sape Lake flood pulse, which is the most productive ecosystem for rice cultivation in Cambodia [21,22] to select ecosystem services associated to rice production systems that benefit the local consumer, before building choice experiment scenarios.

The choice experiment survey was conducted in different places of sale, in the city of Phnom Penh in early 2013. Our application of the choice experiment differs from its application to value food product attributes which tended to rely on a survey protocol presenting different alternatives and the 'buy nothing' scenario as an opt-out format [23,24,25]. For a basic foodstuff such as rice, it is unrealistic to propose a scenario where if none of the situations proposed to the respondent is inappropriate to him/her, he/she can opt to buy nothing. Therefore, respondents are asked to choose between two alternative "scenarios" or continue to buy their current rice, the "choose my current brand" size [26]. Moreover, the application of the choice experiment method to investigate consumers' preference for food products has been an object of strong criticism. Consumers' WTP may be biased when their choices are elicited using pictures instead of real products, and the survey protocol does not introduce any economic incentive to control for their commitment [27]. Recent applications of the CE to study food consumption behavior developing real payment devices using protocol drawn from 
experimental economics studies have initiated a lot of new researches in the lab and in the field [28]. However, real payment treatments have not been established. We thus choose to develop the hypothetical version of the choice experiment. Then, the values of WTP estimated with an econometric model that controls for attribute non-attendance [29, 30] are discussed for better understanding economic behavior underpinning consumer preferences for "organic" or "near-organic" rice attributes.

The remainder of the paper is structured as follows. Section 2 presents the case study and explains the agrarian system approach used to quantify the water ecosystem services delivered by different rice cropping practices. Section 3 summarizes the data collection and the choice experiment design. Section 4 details the econometric modelling. Section 5 shows the results. Last section contains discussion and concluding remarks.

\section{Water ecosystem services and rice cropping in The Tonle Sape Lake}

The Tonle Sap Lake (TSL) is the largest fresh water lake of the Mekong River Basin, and also the largest in Southeast Asia. This part of the world is thus ideal for more traditional methods of rice growing. The region is one of the most suitable agroecosystems for non-irrigated rice cultivation, thanks to increased soil fertility through sedimentation and an abundance of water. However this kind of agro-ecosystem also increases the risk of reduced yields caused by flooding. Improving water management through the construction of dykes and canals for rice terraces serves as an effective flood control solution in the region [31]. The TSL and its floodplain act as a natural water flow regulator for the Mekong River, thus ensure water availability for dry season and receding rice cultivation in Cambodia and Vietnam [32]. As the first Biosphere Reserve in Cambodia, this lake is also classed as one of the world's most productive wetland ecosystems [33]. The flood pulse creates vast areas of seasonal floodplain that serve as habitats for birds and fish. Consequently, intentional production of ecosystem services from rice cultivation in the agro-ecosystems of this region requires an understanding of the trade-offs between food provisioning with other multiple ES supply [34].

This study adopts the Agrarian System Analysis and Diagnosis approach [20]. This field methodology, by exploring how agricultural practices interact with natural ecosystem components contributes to a better understanding of synergies between agricultural practices and ecosystem function, as well as shedding light on the effects of specific land-use and 
management on ecosystem services. The approach is based on an all-encompassing "systemic approach", capable of making sense of agricultural activities at different scale - from the plot level to the regional level - and in a way that accounts for both ecological and socio-economic dimensions. The method consists of gathering data on farmers' decision for their specific plots (land, level of mechanization, labor force) and the ecological impacts of these decisions on the provision of ESs as provided by the natural ecosystem at a larger spatial scale. Thus, a typology approach is developed to group farms with the same cropping practices and to characterize their ability to deliver multiple ecosystem services.

For the case of TSL, socio-economic and ecological data were obtained from interviews with 208 farmers living in 2 districts, Steung Sen (Srayove commune: Srayov Tbong, Roka and Rolous villages) and Santuk (TbPhanhagy, Ompus and Porkhav villages), in 2012-2013. From these data, the TSL rice cropping techniques can be classified into main four types of rice cultivation systems which combine the cropping calendar, rice varieties and technical production chosen by farmers for plots located on different areas of the flood pulse.

The first main cropping technique is called "short-term rice". These systems were adopted sometime around the year 2000 with the aim of better protection against flash flooding during the rainy season. Short-term rice cropping systems are called "dry season rice" by farmers. These non-seasonal and non-photosensitive varieties enable farmers to produce outside of the flood period. There are two different cropping calendars: early seasoning rice and receding rice, for which farmers wait until the water recedes to start re-seeding. Some farmers combine two calendars on the same rice field, enabling them to double their productivity. Water management is important for all of these calendars. Early seasoning rice calls for controlled irrigation, while receding rice requires excellent drainage. Short-term rice cultivation is obtained through the use of agro-chemical inputs such as fertilizer and pesticides. In addition, herbicide use is becoming common practice in reduce plowing.

The second main technique is Rainy season rice cropping. These are traditional practices, with seeds selected naturally and locally from one generation to another. The scientific term for this seasonal rice is "photoperiod sensitive rice varieties". It is often fragrant rice, with which farmers produce Ambok (rice grilled and flattened by crushing) to sell to Phnom Penh at a national event (Water Festival) in November. This main variety is called medium duration of maturity. However, long-term maturity variety grows where there is less water during the 
early rainy season so that they can sow on muddy land. Direct seedlings are used more than transplanting. For rainy season rice, farmers may use pesticides to protect against crabs and rats, and may add chemical fertilizer.

The third main cropping technique is organic rice. Organic rice $(\mathrm{OR})$ is also a rainy season rice. Organic rice is cultivated particularly on high land, to avoid floods even from the natural flood pulse. It has the same life cycle as other medium term rice systems. Because of the risk of flooding, some farmers use only the suitable part of their land for organic rice cultivation and still continue to produce floating rice associated with long term or medium term rice on the rest of their land. Ecological constraints make it possible to produce only outside the floodplain area for the reason that the excessive flooding may cause chemical contamination and as an immediate consequence, the loss of the organic label certification.

The last cropping technique is floating rice. Floating rice is normally a cropping system of rainy season rice but this study keeps it separate because it is particularly suited to deeper water. Many groups of floating rice fields have been converted to short-term rice in the region.

The concept of ecosystem services refers to the biophysical components of ecosystems used by humans, either actively or passively, to improve their wellbeing. To characterize the benefits associated with ES, the Millennium Ecosystem Assessment framework [35] pinpoints different facets of human wellbeing: a need for safety, health, living conditions, social relationships, and economic needs. However, transposing the ecosystem services framework to agro-systems requires the identification of those ESs flowing into agriculture, and those flowing out [36]. The valuation of ecosystem services by local markets can thus succeed for ecosystem services that may benefit urban consumers of rice foodstuffs and other fresh products. Table 1 summarizes the extent to which rice cropping system provides specific ecosystem service (Table A.1 in the appendix details how farming practice and land-use are interlinked with ecosystem functions and services as defined by the MEA framework, as obtained from our field survey and farmers interviews).

The results of table 1 show that none of the rice cultivation systems comply completely with the preservation of all ecosystem services, except floating rice cultivation systems. The 
immediate consequence of this is that differences in the ecosystem services provided by the different rice cultivation system imply a clear trade-off:

- the encouragement of traditional rice cropping (or organic cropping) as opposed to short-term rice cropping for water quality and habitat for agro-biodiversity preservation

- the encouragement of traditional rainy rice cropping as opposed to organic methods, with regard to the cultivation of local variety for the conservation of rice varietal diversity and vice versa (the encouragement of organic rice cropping in comparison with traditional rice cropping) for flood protection

Table 1. The degree with which rice cropping system contributes to the flow of benefits for consumers.

\begin{tabular}{|l|c|c|c|c|c|}
\hline Ecosystem Services & $\begin{array}{c}\text { Expected benefit } \\
\text { for consumer }\end{array}$ & $\begin{array}{c}\text { Intensive } \\
\text { system } \\
\text { dominated } \\
\text { by short- } \\
\text { term rice }\end{array}$ & $\begin{array}{c}\text { System } \\
\text { dominated } \\
\text { by } \\
\text { traditional } \\
\text { medium- } \\
\text { term and } \\
\text { long-term } \\
\text { rice }\end{array}$ & $\begin{array}{c}\text { System } \\
\text { dominated by } \\
\text { organic rice }\end{array}$ & $\begin{array}{c}\text { System } \\
\text { dominated by } \\
\text { floating rice }\end{array}$ \\
\hline $\begin{array}{l}\text { Protection against flood } \\
\text { of agricultural } \\
\text { landscape by the } \\
\text { conservation of flooded } \\
\text { forest }\end{array}$ & Food security & - & - & ++ & +++ \\
\hline $\begin{array}{l}\text { Provisioning of water } \\
\text { quality (for agricultural } \\
\text { uses) }\end{array}$ & $\begin{array}{c}\text { Reduced health } \\
\text { risks from } \\
\text { pesticides } \\
\text { residues in rice } \\
\text { products }\end{array}$ & - & ++ & +++ & +++ \\
\hline $\begin{array}{l}\text { Habitat for agro- } \\
\text { biodiversity fauna, flora } \\
\text { and amphibians of rice } \\
\text { fields }\end{array}$ & $\begin{array}{l}\text { Reduced health } \\
\text { risks from } \\
\text { pesticides } \\
\text { residues in } \\
\text { snacks }\end{array}$ & - & ++ & +++ & +++ \\
\hline $\begin{array}{l}\text { Conservation of } \\
\text { traditional rice variety }\end{array}$ & $\begin{array}{l}\text { Cultural heritage } \\
\text { value }\end{array}$ & -- & +++ & ++ & +++ \\
\hline
\end{tabular}

Note: -:Moderate Negative impact; --:High negative impact ; ++:Moderate positive impact; +++: High positive impact.

Market-based incentives could be a helpful tool in ensuring the preservation of ecosystem services, and increasing farmers' income. To this end, it is important to identify the preference of local consumers for ecosystem services flows from these rice cropping systems to make payment mechanisms both credible and financially sustainable. We therefore decided to value 
three ecosystem services that serve the nutrition, security, safety and health of consumers: provision of water quality in the river, provision of habitats for agro-biodiversity, and the protection of the agricultural landscape from flooding. We consider the conservation of traditional rice variety as an ecosystem service provided by traditional rice cropping system. Rice-based agricultural ecosystems are indeed an important support for cultural services in Asian country.

\section{Survey design and data collection}

\subsection{Sampling method}

Data were collected from a 2013 survey conducted in Phnom Penh, which is the largest city and capital of Cambodia with a population of 1.5 million in 2013. Phnom Penh was chosen for two reasons. First, Phnom Penh represents about 50\% of the total urban population in the country. Second, Phnom Penh City was host for most of new stores where labelled organic products are sold in Cambodia. However exploratory research generally uses purposeful, conceptual sampling instead of random sampling. So our sampling strategy was driven by the need to find different consumers from differing backgrounds and consumer purchasing habit, rather than representativeness of the general population in statistical terms. Our survey design therefore focused initially on the inner center of the city of Phnom Penh (the municipality of Boeung Keng Kang) where the upper and middle classes live. We then moved south-west toward Stung Mean Chey municipalities where lower class people live. We included all the three types of food distribution system such as traditional markets, supermarkets and organic shops. To cover the widest possible range of buying habits for different socio-professional categories, the surveys were conducted early and late in the day, both during the working day and at the weekend. The main survey consisted of face-to-face interviews conducted at traditional markets ( $41 \%$ of the sample), supermarkets (10\% of the sample) and organic shops (39\% of the sample).

The questionnaire made up of four sections. The first part included questions about the respondent's socio-economic and demographic status. The second part contained questions about respondents' perception on the environmental impact of agriculture practices and ecosystem services. The third part consisted of questions about the respondents' buying habits (and those of their household) including organic food. The fourth section was the choice experiment itself. 


\subsection{Choice Questionnaire}

Respondents in our survey were asked to make choices between various specifications of rice product. Each product was described by an intrinsic quality attribute (rice fragrance), two extrinsic attributes: the presence of a label (or not) that indicates the agricultural production method, and targeted ecosystem service; and the price variable. Two levels were used to depict the type of rice: fragrant versus normal rice. The label attribute distinguishes certified organic rice, certified chemical free rice, non-certified chemical free rice and chemically grown rice as a reference. The attribute for targeted ecosystem services is defined by four considerations: the preservation of water quality and biodiversity of the river; the conservation of flooded forests; the preservation of local rice varieties; or no specific ecosystem service. The payment vehicle was expressed in price per $\mathrm{kg}$. This cost attribute obtained four different levels ranging from 3000 riels to 7000 riels. The attributes and their levels are reported in Table A. 2 in the appendix.

Table 2: Example of choice set used in the survey

\begin{tabular}{|c|c|c|}
\hline Scenario 1 & Scenario 2 & I don't change my consumption. \\
\hline Fragrant rice & Normal Rice & Which rice?............ \\
\hline $\begin{array}{c}\text { Rice certified grown without } \\
\text { chemical use }\end{array}$ & Rice grown with chemical use \\
\hline $\begin{array}{c}\text { Protection against flood of } \\
\text { agricultural landscape by the } \\
\text { conservation of flooded forest }\end{array}$ & Preservation of local rice variety & \\
\hline Riels 4,500 & Riels 6,000 & \\
\hline$\square$ & $\square$ & $\square$ \\
\hline
\end{tabular}

In order to decide exactly which combinations of attributes respondents should be asked to choose, a fractional generation procedure using Ngene software was used to form an orthogonal main effect design of scenarios. The procedure has identified thirty six choice sets that were later split into three blocks. Each respondent was then faced with six choice tasks. In each task, respondents were told to examine two alternatives, to choose between these 
alternatives or their current consumption. Table 2 depicts one of the choice sets situation presented to survey respondents.

\subsection{Socio-economic characteristics of survey participants}

The questionnaire was administered to 300 respondents. After data clearing, 295 individuals were included in the analysis. The average age of respondents was 31 years old, and $90 \%$ of them were under forty. Forty-eight percent of respondents were the spouse of the head of household and $36 \%$ were the head of household. Forty-six percent were women. Related to their education level, 44\% of people held a high-school leaver's diploma. This shows that our respondents were reasonably well educated people. The result shows that the majority of head of household and respondent (90\%) are Khmer and around 10\% are foreigners (coming from a Western country, Chinese or other country).

The survey reveals that $67 \%$ of respondents declare consuming (regularly or occasionally) certified organic products including rice that they buy from the different branches of CEDAC (Center for Study and Development in Agriculture) shops. Only 33\% stated that they never consumed any certified organic products. Among people who recognised organic labels, 51\% stated that they knew CEDAC labels ("fair-trade" and "organic certified" agricultural products). In contrast, only $2 \%$ stated that they knew the Cambodian Organic Agriculture Association (COrAA) label, which is the national certification body (also responsible for certifying organic products sold in CEDAC shops). The preservation of health was quoted by $95 \%$ of the sample as the main motivation for consuming organic products, followed by food quality. Sixty-six percent of those surveyed stated that they consumed organic products because they are "locally produced" food. 53\% stated that they consumed organic products because they found it tastier than non-organic food. Approximately half of respondents stated that they consumed organic food to support farmers' income. Finally, $48 \%$ of those surveyed stated that they consumed organic products to preserve the natural environment. Among respondents who had never tried organic foods, $54 \%$ stated that they did not consume organic products because they did not know where to buy them.

\subsection{Choice data quality}

Each respondent completed 6 choice tasks, with each task including three choice scenarios, resulting in 1770 observations for the 295 people retained for the analysis. In the CE, 40 
respondents (14\%) always chose to stay with their existing rice. In order to better understand possible reasons for opting for "status-quo scenarios" the participants complete an open follow-up question after each choice task. We did not observe any signs of protest answers for such choices. Only two respondents mentioned the price. The rest of the respondents gave arguments related to the taste and quality of their current rice. Out of all the respondents who selected alternative rice scenarios, 131 (44\%) never chose their current rice.

\section{Econometric modelling framework}

Choice experiment has its theoretical foundation in Lancaster's multi-attribute utility theory and Mcfadden's random utility model. It is now usual to formulate that the benefit provided to an individual $i$ for the choice of scenario $j, j=1,2,3$ between multiple alternatives of a choice set $n, n=1,2, \ldots, 6$, is a function of the level of the scenarios' attributes and a random term. Thus, the utility function of the respondent can be expressed as follows:

$$
U_{i j n}=\alpha_{j}+\beta^{\prime} X_{j n}+\varepsilon_{i j n}
$$

where the parameter $\alpha_{j}$ represents the specific constant for alternative $j$. The vector $X_{j}$ corresponds to the levels of scenarios' attributes. The values of $X_{j}$ are set to zero for the status-quo alternative "Choose my own rice". The vector $\beta$ represents parameters to be estimated, and $\varepsilon$ is the stochastic element.

When faced with different alternatives, the respondent is assumed to select the alternative that gives him or her highest level of utility. The probability $\pi$ that an individual $i$ chooses alternative $j$ from the choice set $n$ is then given by the following decision:

$$
\pi_{i j n}=\operatorname{Pr}\left\{\alpha_{j}+\beta^{\prime} \mathrm{X}_{\mathrm{jn}}+\varepsilon_{i j n} \geq \alpha_{k}+\beta^{\prime} \mathrm{X}_{\mathrm{kn}}+\varepsilon_{i k n} ; j \neq k, \forall j=1,2,3\right\}
$$

The conditional logit model is the first candidate to estimate the choice probabilities in equation (2). Assuming that the error terms $\varepsilon$ are independently and identically distributed 
(IID) and follow the Gumbel distribution, the probability that alternative $j$ would be chosen from choice set $n, n=1,2, \ldots, 6$ is calculated with the following equation:

$$
\pi_{i j n}=\frac{\exp \left(\beta^{\prime} X_{j n}\right)}{\sum_{j=1,2,3} \exp \left(\beta^{\prime} X_{j n}\right)}
$$

Each scenario alternative may have four major effects on an individual utility: a quality effect with respect to rice fragrance, the guarantee of health effect through the elimination of pesticide residues on food from agricultural methods and their certification, and an environmental effect from ecosystem service provided by rice cultivation system. However, local consumers in developing countries have a very limited budget, which may complicate their purchasing decision and ability to make trade-offs between the several characteristics of organically-grown rice and its price through the choice processes. Several studies give proof for lower price sensitivity of organic products demand [37]. Furthermore, some studies get out the idea that households in developing countries are more reluctant to pay for environmental protection because they are not willing to reduce their private spending to finance a public good [38]. From these, we can derive the suggestion that some respondents may ignore the price to make their choice.

Applying stated preference techniques in order to capture the value that individuals place on biodiversity and ecosystem preservation has raised intensive debate [39]. Respondents are supposed to make their choice based on their prior knowledge. However, if the individuals taking part in the study are not sufficiently well informed about the benefits of protecting the environment, they will underestimate the importance of preservation programmes. Consequently, when the abstract nature of ecosystem services could be an obstacle to widespread understanding and recognition of the benefit of specific ecosystem service preservation, particularly if there are low levels of literacy [40], we cannot exclude the fact that some respondents may also ignore the environmental attributes during the choice experiment survey.

Choosing the appropriate econometric method estimation to deal with attribute nonattendance in choice experiment requires clarification of the sources of the phenomenon [41]. In our case, such behavior may reflect well theoretically founded phenomenon (maximization of utility subject to budget constraint) as well as the heterogeneity of decision-process making 
of respondents regarding the choice task and its cognitive complexity. Thus, in a similar fashion to Hole [30], we developed an endogenous attribute attendance (EAA) model to process choice probabilities. The decision-making process thus followed a two-step process, whereby the respondent first decides which attributes to take into account when comparing the available alternatives, including his/her own rice. Then, he/she chooses the preferred alternative conditional of the set of attributes chosen in stage one. The EAA is equivalent to the equality-constrained latent class analysis developed by Scarpa et al. [29] for an inferred approach to ANA. The main advantage of EAA over this approach is that all possible attributes subset can be examined by the model.

To be more precise, when faced with a total of $l, l=4$ attributes for each alternative, the respondent will choose a subset of attributes $C_{s}(l)$ to take into account when valuing an alternative: $C_{s}(l)=\lambda_{s} Z_{i}+\zeta_{i s}$ where $Z_{i}$ is the vector of observed individual socioeconomic characteristics, $\lambda_{\mathrm{s}}$ is a vector of parameters to be estimated, and $\zeta_{\text {is }}$ is the error terms. The total number of subset of attributes $s$ is 16 for our case. The probability that individual $i$ opted for $C_{s}(l)$ is given by the following equation:

$$
C_{i s}^{*}(l)=\frac{\exp \left(\lambda_{s} Z_{i}\right)}{\sum_{s=1, \ldots, 16} \exp \left(\lambda_{s} Z_{i}\right)},
$$

Then, if we assume the existence of ANA behaviour within our population, the utility function presented by equation (1) and probability choice formulated in equation (3) have to be rewritten to account for the fact that an individual $i$ derives its utility from the choice of alternative $j$ based on the choice of subset of attributes he/she makes at the first stage. The expressions of these two equations are now: $U_{i j n}^{s}\left(C_{s}(l)\right)=\alpha_{j}+\beta_{s}^{\prime} X_{j n}^{s}+\mathcal{E}_{i j n}^{s}$, and $\pi_{i j n}^{s}\left(C_{s}(l)\right)=\frac{\exp \left(\beta_{s}^{\prime} X_{j n}^{s}\right)}{\sum_{j=1,2,3} \exp \left(\beta_{s}^{\prime} X_{j n}^{s}\right)}$.

The unconditional probability of the observed sequence of choices for the $n, n=1,2, \ldots, 6$ choice sets is now: 


$$
P_{i n}=\sum_{s=1}^{16}\left\{\prod_{n=1}^{6} \pi_{i j n}{ }^{s} \times C^{*}{ }_{i s}(l)\right\}
$$

The module eaalogit implemented also by Hole ([30]) to perform an estimation of parameters of equation (6) by maximum likelihood procedure. Then, we compare the results of the eaalogit model to the estimation latent class logit model to find out how attribute nonattendance in this choice experiment study may manifest within such classical approach.

\section{Econometric estimations and results}

\subsection{The eaa logit model}

The empirical analysis is thus based on the estimation of equation (6) by maximum likelihood. We elected to use effect-coded dummy variable to define the value of all nonmonetary attributes. This allows us for nonlinear effects of attribute levels on utility. The price per kilo is proposed as a continuous variable. The individual utility function thus includes eight variables for attribute levels, and an alternative specific constant for opt-out. Attribute attendance probability was supposed to be affected by two main individual characteristics: household income and education attainment of respondent. A first estimation of a conditional logit choice with endogenous attribute attendance (eealogit) indicates that the probability of attribute attendance is not influenced by respondent characteristics. It was found that neither the educational attainments of respondents nor their household income (or instead households size) had any effects on the probability of considering a given attribute.

These results direct us toward a different interpretation of the factors behind the ANA in this study, since respondents who show ANA behavior cannot be represented by their observable characteristics. It cannot be ruled out that non-attender respondents choose to focus on one attribute over another for many other unknown reasons [42]. We thus estimated another version of our eealogit model for which no explanatory variable appears in the attribute attendance probability equation, except a constant term and an error term. The results of this estimation are shown in Table 3 column 2 and 3. We also estimated a version of the eaa logit model which accounted for the fact that individual characteristics may affect preferences for opt-out option. Initially, a set of socio-economic variables were included one by one (age of the respondent, household size, educational attainments, income level, actual organic consumer) in the utility function through interaction terms with the dummy code for opt-out 
scenario. These interactions terms were not significant in the model except for the indicator variable for actual organic consumer. Based on the AIC and the BIC, we consider that the eealogit specification was this last model.

Table 3. Econometric estimation results of the EAA model

\begin{tabular}{|c|c|c|c|c|}
\hline & Model 1 & & Model 2 & \\
\hline Choice & Coefficient & z-score & Coefficient & Z-score \\
\hline Opt-out & $9.89^{* * *}$ & 14.24 & $10.30 * * *$ & 14.51 \\
\hline Opt-out $*$ Organic consumer & & & $-0.65^{* *}$ & -2.01 \\
\hline Price & $-0.001 * * *$ & -14.37 & $-0.001 * * *$ & -13.90 \\
\hline \multicolumn{5}{|l|}{ Taste attribute } \\
\hline Fragrant rice & $0.15^{*}$ & 1.74 & $0.15^{*}$ & 1.67 \\
\hline \multicolumn{5}{|l|}{ Labelling attribute } \\
\hline Certified organically produced rice & $2.29 * * *$ & 14.46 & $2.29 * * *$ & 14.53 \\
\hline Certified chemical free produced rice & $2.07 * * *$ & 11.64 & $2.08 * * *$ & 11.74 \\
\hline Non certified chemical free produced rice & $1.27 * * *$ & 7.78 & $1.27 * * *$ & 7.82 \\
\hline \multicolumn{5}{|l|}{ Ecosystem service attribute } \\
\hline $\begin{array}{l}\text { Preservation of water quality and } \\
\text { biodiversity }\end{array}$ & $1.36 * * *$ & 10.19 & $1.36^{* * *}$ & 10.19 \\
\hline Preservation of flooded forest & $1.60^{* * *}$ & 10.00 & $1.59^{* * *}$ & 9.95 \\
\hline Conservation of local variety & $1.28 * * *$ & 6.45 & $1.24 * * *$ & 6.35 \\
\hline \multicolumn{5}{|l|}{ Attribute non-attendance } \\
\hline $\begin{array}{l}\text { Predicted probability of non-attendance } \\
\text { for price attribute }\end{array}$ & $0.60 * * *$ & 13.46 & $0.61 * * *$ & 13.93 \\
\hline $\begin{array}{l}\text { Predicted probability of non-attendance } \\
\text { for labelling attribute }\end{array}$ & 0.04 & 0.72 & 0.04 & 0.66 \\
\hline $\begin{array}{l}\text { Predicted probability of non-attendance } \\
\text { for ecosystem service attribute }\end{array}$ & $0.17 * * *$ & 2.81 & $0.17 * * *$ & 2.89 \\
\hline Log-likelihood & & -1291.77 & & -1289.76 \\
\hline AIC & & 2607.55 & & 2605.52 \\
\hline BIC & & 2686.48 & & 2691.03 \\
\hline Number of observations & & 5310 & & 5310 \\
\hline Number of individuals & & 295 & & 295 \\
\hline
\end{tabular}

Note: *: significant at $10 \%$; ** significant at $5 \%$; ***: significant at $1 \%$

Table 3 column 4 and 5 reports the predicted attribute probability non-attendance based on the last estimation of the eealogit model. It can be seen from these results that a substantial share of respondents (about $61 \%$ of the sample) ignored the "price" attribute. The proportion of 
respondents taking price into account must be borne in mind when quantifying and interpreting the willingness to pay (WTP) estimates and interpretation. All respondents were assumed to have attended to "fragrant attribute" to make their choice. It is not a surprise that only $4 \%$ of respondents ignore the label attribute, as a large proportion (67\%) of those surveyed stated that they had experience of organic food. The attribute for "targeted ecosystem services" was also considered more frequently, but still ignored by $17 \%$ of respondents.

Table 3 column 4 presents the utility function. The opt-out option is associated to a positive and significant coefficient, meaning that the majority of respondents prefer their actual rice. However, organic consumers are willing to pay for alternative rice qualities. As expected, the parameter estimate on the variable price is negative and significant indicating that an increase in the price of a rice product entailed a reduced utility level. The quality of the rice was positive and statistically significant only at p-value set at $10 \%$, meaning that the majority of the respondents are quite indifferent between fragrant and normal rice. All three variables indicating that the agricultural production method was chemical-free were positive and significant, indicating that safer products do indeed increase utility. Rice grown with organic production methods provides the highest utility, followed by rice grown without chemical use either the production method was certified chemical free or not. Environmental attributes also have significant and positive impact on the consumer's utility.

\subsection{The latent class model}

The latent class model allows individuals to be grouped into relatively homogeneous classes of preference (i.e. individuals who belong to the same class exhibit identical choice behaviour). The model estimates the membership probability in each class and the utility functions specific to each class. Thus, we can assume the existence of classes of preferences within our population, according to individual perception of the attributes and the possibility of similar attribute non-attendance strategies. We thus expect one or more classes for which the coefficient of price attribute and labelling attribute levels to be equal to zero.

The first step of the econometric procedure for the latent class approach of choice probability corresponds to the estimation of class membership function. In order to determine the optimal number of classes, with three attributes, we tested 2 to 5 class solutions where the probability 
model for class selection did not include any socio-economic variables as factor of class membership. They are not significant and were removed from the model. We used the most used criteria to determine the number of classes: the minimum Bayesian Information Criterion (BIC). These statistics support three classes as the optimal solution (test results for different number of classes are provided in the appendix A3). The choice equation has thus to be constructed according to three classes of preferences. The econometric estimation of the choice equation with the same set of explanatory factors as for the eaalogit model provides differentiated parameters for each class.

Table 4 - Coefficient Estimates with latent class logit

\begin{tabular}{|c|c|c|c|c|c|c|}
\hline & \multicolumn{2}{|l|}{ Class 1} & \multicolumn{2}{|l|}{ Class 2} & \multicolumn{2}{|l|}{ Class 3} \\
\hline & Coefficient & z-score & Coefficient & z-score & Coefficient & z-score \\
\hline Opt-out option & $21.99 * * *$ & 5.18 & $8.96^{* * *}$ & 9.58 & $5.22 *$ & 1.66 \\
\hline Opt-out option*Organic consumer & $-4.03 * * *$ & -5.43 & -0.37 & -1.00 & $2.88 * * *$ & 3.71 \\
\hline Price & $-0.001 * * *$ & -5.45 & $-0.0001 * * *$ & -3.85 & $-0.001 * * *$ & -5.15 \\
\hline Fragrant rice & 0.43 & 1.45 & 0.07 & 0.62 & 0.53 & 1.13 \\
\hline Certified organically produced rice & $4.40^{* * *}$ & 4.13 & $2.16^{* * *}$ & 11.53 & 1.14 & 1.63 \\
\hline Certified chemical free produced rice & $3.86^{* * *}$ & 3.87 & $1.94 * * *$ & 8.74 & 0.20 & 0.26 \\
\hline $\begin{array}{l}\text { Non-certified chemical free produced } \\
\text { rice }\end{array}$ & $3.14 * * *$ & 3.09 & $1.21 * * *$ & 6.51 & 0.30 & 0.34 \\
\hline $\begin{array}{l}\text { Preservation of water quality and } \\
\text { biodiversity }\end{array}$ & $1.21 * * *$ & 2.88 & $1.24 * * *$ & 7.32 & $2.10^{* * *}$ & 2.63 \\
\hline Preservation of flooded forest & $1.60 * * *$ & 3.28 & $1.49^{* * *}$ & 6.01 & 0.87 & 1.26 \\
\hline Conservation of local variety & $1.20 * * *$ & 2.36 & $1.01 * * *$ & 3.70 & $2.52 * * *$ & 3.27 \\
\hline Log-likelihood & -1262.57 & & & & & \\
\hline AIC & 2589.14 & & & & & \\
\hline Probability of class membership & 0.24 & & 0.59 & & & 0.17 \\
\hline Number of observations & 5310 & & & & & \\
\hline Number of individuals & 285 & & & & & \\
\hline
\end{tabular}

Note: *: significant at $10 \% ; * *$ : significant at $5 \% ; * * *$ : significant at $1 \%$

The results of estimation are displayed in Table 4. Class 1 represents $24 \%$ of respondents. Class 2 represents $59 \%$ of the sample, and class 3 accounts for $17 \%$ of the sample. We observed that for all three classes of preferences, the coefficients associated with the price attribute are negative and significant, and we found important contrast between the estimated value for class 2 and coefficient estimates for class 1 and 3 : the value of the coefficient is ten times lower indicating individuals whose choices are grouped in class 2 have a totally different preference for this attribute. Class two merge individuals who may perceive the price attribute much larger. We cannot exclude the fact that class 2 will merge respondents who 
could be considered as non-attenders or more precisely low attenders for price with eaalogit model. Contrary to Hensher et al. (2012) [42], we believe that the situation of limited budget in developing country may lead respondents to perceive price attribute levels too high in such a way that only price levels below a certain amount are taken into consideration.

We also find out that only in class 3 that coefficient estimates for labelling attribute levels are statistically non-significant. These results may indicate that class 3 merge individuals who are not sensitive to labelling attribute. The coefficient of the interaction term between opt-out option and indicator variable for actual organic consumer is positive and statistically significant, meaning that organic consumers perceive higher benefit when choosing to stay with their actual rice compared to proposed alternative rice qualities. This is in contrast to the reported result in class 1 choice equation.

\subsection{Marginal WTP estimates}

Our objective for this study was not to identify the Participants" "ideal" rice product, but to assess their willingness to pay (WTP) for different attributes that can define traditionally grown rice compared with standard rice grown with chemical fertilizer pesticides. First of all, we find that $40 \%$ of the respondent has a positive WTP in this study since they attend the price attribute. This does not mean that the remaining $60 \%$ who have neglected the price does not value the attributes considered. But as part of this investigation, they have not considered the price to make their choice. The distribution of WTP shown in Table 5 only concerns those who considered the price level to make their choice. The results presented in column 2 and 3 correspond to estimated WTP values inferred from the parameters of the eaalogit model. While the WTP estimates inferred from the two estimations are not comparable, Table 5 (column 4 to 7) also provides distribution of WTP values inferred from parameters of class 1 and class 3 choice equations of the latent logit model. It is worth noting that the WTP estimates for the two classes differ since each model is subject to different individual preferences and attribute attendance behavior.

Based on the eaalogit model (which provides a better fit for the overall choice model), the mean value of the willingness to pay for organic certified grown rice (compared with standard rice grown with chemical fertilizer and use of pesticide) is $3587 \mathrm{riels} / \mathrm{kg}$ with a standarddeviation of 1343 riels $/ \mathrm{kg}$. This value seems reasonable. Currently, the price differential 
between normal white rice (PhakChney) and organic certified grown rice is about 1000riels $/ \mathrm{kg}$. Labels play the role of signal for the consumer and help them assess product quality that can positively affect their utility [43]. As such, certification procedures are important because they affect confidence of consumer on the label that have to differentiate production methods. In this study, it appears that individuals do not make difference between "organic label" and "free-chemical label", which is valued (about 3261riels/kg). Finally, they less value a rice product without chemistry (but not necessarily one which is certified) with a price premium of 1988riels per kilo.

The results also show that the preservation of the quality of rivers and their biodiversity wins the support of consumers. Over $83 \%$ of respondents gave importance to ecosystem service attributes. The mean values of the WTP to maintain the SE by rice cultivation, of those who take into consideration price are : 2138riels / $\mathrm{kg}$ for water and biodiversity; the 2488riels/kg for the preservation of flooded forests for protection against flooding; and 1950 riels $/ \mathrm{kg}$ for the conservation of local variety.

Table 5. Distribution properties of marginal willingness to pay values (in riels 2013)

$($ Krinsky and Robb method, number of replications $=1000)$

\begin{tabular}{|c|c|c|c|c|c|c|}
\hline \multirow[t]{2}{*}{ Attribute name } & \multicolumn{2}{|l|}{ Eaalogit } & \multicolumn{2}{|c|}{ Latent class/Class 1} & \multicolumn{2}{|c|}{ Latent class/Class3 } \\
\hline & Mean value & $\begin{array}{l}\text { Standard- } \\
\text { deviation }\end{array}$ & Mean value & $\begin{array}{l}\text { Standard } \\
\text { deviation }\end{array}$ & Mean value & $\begin{array}{r}\text { Standard } \\
\text { deviation }\end{array}$ \\
\hline Fragrant rice & - & - & - & - & - & - \\
\hline $\begin{array}{l}\text { Certified organically } \\
\text { produced rice }\end{array}$ & 3587 & 1343 & 6929 & 7412 & - & - \\
\hline $\begin{array}{l}\text { Certified chemical free } \\
\text { produced rice }\end{array}$ & 3261 & 1303 & 6066 & 7061 & - & - \\
\hline $\begin{array}{l}\text { Non certified chemical } \\
\text { free produced rice }\end{array}$ & 1988 & 1168 & 4939 & 6347 & - & - \\
\hline $\begin{array}{l}\text { Preservation of water } \\
\text { quality and biodiversity }\end{array}$ & 2138 & 923 & 1899 & 3028 & 1623 & 2599 \\
\hline $\begin{array}{l}\text { Preservation of flooded } \\
\text { forest }\end{array}$ & 2488 & 1191 & 2519 & 3574 & - & - \\
\hline $\begin{array}{l}\text { Conservation of local } \\
\text { variety }\end{array}$ & 1950 & 1388 & 1881 & 3636 & 1945 & 2563 \\
\hline
\end{tabular}




\section{Discussion and conclusion}

The choice experiment we used provided respondents with an environment that is more comparable to a real shopping experience where a consumer can decide between different options or not to buy their normal product. Our results suggest that consumers are willing to pay more for rice produced using chemical-free methods. In addition, our respondents value the certified organic certified grown rice over certified rice grown using chemical-free methods. Furthermore, the price premium currently charged for organic rice is higher than the price premium as observed in the local market. Organic rice sells for a premium price, mainly because the production, processing, procurement and distribution costs are higher than for rice produced using conventional methods. The niche market situation (supply lower than demand) of organic food products may also lead to higher prices. Higher WTP value than the price premium in the market indicates that the consumer is willing to pay an additional premium price since they perceive it as healthier and of better quality [44].

Another major aspect of this study is that consumers express additional values for the preservation of biodiversity and river water quality ecosystem services related to rice cultivation systems. Environmental protection activities that also benefit other citizens get the same support from consumers as their healthiness counterpart conveyed by the presence of an organic label. This is in contrast to other major studies' findings, which conclude that the purchase of organic products is mainly motivated by self-interested concerns relating to health, quality and taste; rather than ecological concerns relating to the environment. Durham et al. [45] is one exception to this. However, their results concern people living in developed countries. This last result is particularly important when considering that those who reported eating organic products in Cambodia, are motivated more by preserving their health than by protecting the natural environment. This shows that there is a demand for water quality in rivers to be protected, along with aquatic species. In addition, residents of large cities are willing to pay higher price premiums to support production methods that promote these specific public goods as ecosystem services.

The WTP values obtained by this exploratory study thus represent new figures for an organic rice product targeting the local market. The "organic" certification has been promoted by national governments, NGOs or international institutions. These different actors see in this tool a means to reduce rural poverty by using the price premium promised by the Niche 
market of organic food [46]. However, the development of certified 'organic farming' which targets the local market faces both organizational and ecological constraints. Organic practices are often the best solution for poor farmers, because no additional funding is required to buy additional inputs. However, low yield associated with this organic technique compared to conventional ones [47] dissuade farmers from adopting such practices. This economic argument is reinforced by ecological constraints. For the case of rice cultivation in the TSL on which the agrarian analysis of this study is based, natural flooding is the main ingredient for organic rice production. However, chemical contamination of a rice field in the event of flash floods can result in the immediate loss of the organic label. Faced with this risk, farmers opt to sell their rice on the local market without using the marketing network of certified products.

The results of this study open new perspectives on two fronts. Firstly, rice cultivation systems that preserve the quality of rivers and habitats for agro-biodiversity need to benefit from a price premium. A proportion of urban consumers are willing to contribute to the preservation of this ecosystem service, whether they are already organic consumers or not. Organic certification is still very selective. The challenge for market-based environmental policy instruments, in this specific case of rice cultivation, is thus to find innovative certification strategy that generates win-win-win solutions [48], optimize anticipated price-premiums for farmers, foster consumer confidence in the health and nutritional benefits of rice products, and preserve ecosystem functions and services.

The attribute attendance issue is one of the hottest theoretical and empirical topics being currently opened by economic valuation in the case of payment for ecosystem services in the developing world. The results of the exploratory analysis in this study confirm that choice experiment application to this subject area should take into consideration non-attendance behavior. However, questions related to protocol surveys and the best econometric methods to capture such behavior are still relatively unanswered [49].

\section{Bibliography}

[1] D. G., Bottrell, K. G., Schoenly, Resurrecting the ghost of green revolutions past: The brown planthopper as a recurring threat to high-yielding rice production in tropical Asia, J. Asia Pac. Entomol. 15(2012) 122-140.

[2] D. J., Ecobichon, Pesticide use in developing countries, Toxicology, 160 (2001) 27-33. 
[3] J., Popp, K., Pető, J., Nagy, Pesticide productivity and food security. A review, Agron. Sustain. Dev. 33(1) (2013) 243-255.

[4] M.,Halwart, Biodiversity, nutrition and livelihoods in aquatic rice-based ecosystems Biodiversity 9 (2008) 36-40.

[5] L., Colby, B. M., Michael, M., Keavuth, H. D., Kong, C. L., Nareth, C., Barney, S., Teak, Wildlife decline in Cambodia, 1953-2005: exploring the legacy of armed conflict, Wiley Periodical 211 (2009).

[6] S., Milne, W. M., Adams, Market Masquerades: Uncovering the Politics of Communitylevel Payments for Environmental Services in Cambodia, Dev. Change. 432 (2012) 622-622.

[7] T. P., Balzer, S., Pon, Traditional use and availability of aquatic biodiversity in rice based ecosystems: I. Kampong Thom Province, Kingdom of Cambodia. Awareness of Agricultural Biodiversity, In: Halwart, M., Bertley, D., H., Guttman, FAO, 2002, MRC: 17.

[8] M., Halwart, Biodiversity and nutrition in rice-based aquatic ecosystems, J. Food Compos. Anal. 19 (2006) 747-751 doi:http://dx.doi.org/10.1016/j.jfca.2006.03.012

[9] P., Pugliese, Organic farming and sustainable rural development: a multifaceted and promising convergence, Sociol. Rural. 41 (2001) 112-130.

[10] D. Rigby, D. Cáceres, Organic farming and the sustainability of agricultural systems, Agr. Syst. 681 (2001) 21-40.

[11] O. I., Ayuya, E. O., Gido, H. K, Bett, J. K., Lagat, A. K., Kahi, S., Bauer, Effect of certified organic production systems on poverty among smallholder farmers: empirical evidence from Kenya, World Dev.67 (2015) 27-37.

[12] A., Krystallis, G., Chryssohoidis, Consumers' willingness to pay for organic food: Factors that affect it and variation per organic product type, Brit. Food J., 1075 (2005) 320343.

[13] J. C., Milder, S. J.Scherr, C., Bracer, Trends and future potential of payment for ecosystem services to alleviate rural poverty in developing countries, Ecol. Soc. 152 (2010).

[14] E., Gomez-Baggethun, R., de Groot, P.L., Lomas, C., Montes, The history of ecosystem services in economic theory and practice: from early notions to markets and payment schemes Ecol. Econ., 69 (2010) 1209-1218.

[15] V., Boisvert, P., Méral, G. Froger, Market-based instruments for ecosystem services: institutional innovation or renovation? Soc. Nat. Res. 2610 (2013).

[16] L., Van Kempen, R., Muradian, C., Sandóval, J.P., Castañeda, Too poor to be green consumers? A field experiment on revealed preferences for firewood in rural Guatemala, Ecol. Econ. 687 (2009) 2160-2167. 
[17] M., Mergenthaler, K.,Weinberger, M. Qaim, Consumer valuation of food quality and food safety attributes in Vietnam, Appl. Econ. Perspect. Pol. 312 (2009) 266-283.

[18] O. O., Ibitoye, M., Nawi, N., Kamarulzaman, N., Hirawaty, M., Norsida, Consumers' awareness towards organic rice in Malaysia, Int. Food Res. J., 215 (2014) 1711-1718.

[19] B., Burkhard, A., Müller, F., Müller, V., Grescho, Q., Anh, G., Arida, J. V., Bustamante, Ho V., Chien, K.L., Heong, M., Escalada, L., Marquez, D. T., Truong, J., Villareal, J., Settele, Land cover-based ecosystem service assessment of irrigated rice cropping systems in southeast Asia-An explorative study, Ecosystem Services, 14 (2015) 76-87.

[20] H., Cochet, Origine et actualité du " Système Agraire " : retour sur un concept, Revue Tiers Monde, 3 (2011) 97-114.

[21] D., Pillot, Jardins et rizières du Cambodge: les enjeux du développement agricole, (2008), Karthala.

[22] P., N., Someth, H. T., Kubo, S., Ly, Ring dike system to harness floodwater from the Mekong River for paddy rice cultivation in the Tonle Sap Lake floodplain in Cambodia, Agric. Water Manage. 961 (2009) 100-110.

[23] F., Carlsson, P., C. Frykblom, J., Lagerkvist, Consumer benefits of labels and bans on gm foods-choice experiments with swedish consumers, Am. J. Agr. Econ 891 (2007)152161.

[24] R., Wongprawmas, M., Canavari, Heterogeneity in consumer preferences for food safety level in Thailand, 143rd Joint EAAE/AAEA Seminar, 2015, Naples, Italy 202744, European Association of Agricultural Economists.

[25] J., Garcia-Yi, Willingness to pay for organic and fairtrade certified yellow chili peppers: Evidence from middle and high income districts in Lima, Peru, Brit. Food J., 1172 (2015) $929-942$.

[26] A. Kontoleon, M. Yabe, Assessing the impacts of alternative 'opt-out' formats in choice experiment studies: consumer preferences for genetically modified content and production information in food, IJPAR, 5 (2003) 1-43.

[27] J. L. Lusk, T. C. Schroeder, Are choice experiments incentive compatible? a test with quality differentiated beef steaks, Am. J. Agr. Econ., 862 (2004) 467-482.

[28] R., Moser, R., Raffaelli, S., Notaro, Testing hypothetical bias with a real choice experiment using respondents' own money, Eur. Rev. Agric. Econ., 19 (2013) 1-22.

[29] R., Scarpa, R., Zanoli, V., Bruschi, S., Naspetti, Inferred and stated attribute nonattendance in food choice experiments, Am. J. Agr. Econ., 17 (2012). 
[30] A. R., Hole, A discrete choice model with endogenous attribute attendance, Econ. Lett., 1103 (2011) 203-205.

[31] T., P. T., Masumoto, K., Shimizu, Impact of paddy irrigation levels on floods and water use in the Mekong River basin, Hydrological Processes, 229 (2008) 1321-1328.

[32] P., L. S., Ly, T. B., Bruun, D., Rutz, A., de Neergaard, The system of rice intensification: Adapted practices, reported outcomes and their relevance in Cambodia,

Agr. Syst., 1130 (2012) 16-27.

[33] UNESCO, Tonle Sap Biosphere Reserve." Biosphere Reserves Retrieved 05 August, 2013, from http://www.unesco.org/new/en/phnompenh/natural sciences/biospherereserves/ tonle-sap-biosphere-reserve/.

[34] S. M., Swinton, F., Lupi, G. P., Robertson, S. K., Hamilton, Ecosystem services and agriculture: Cultivating agricultural ecosystems for diverse benefits, Ecol. Econ., 642 (2007) 245-252.

[35] Millennium Ecosystem Assessment Ecosystems and Human Well-Being: Synthesis. I. , 2005, UN Press, Washington DC.

[36] W., Zhang, T. H., Ricketts, C., Kremen, K., Carney, S. M., Swinton, Ecosystem services and dis-services to agriculture, Ecol. Econ., 64 (2007) 253-260.

[37] M., Stolz, H., Stolze, M.,Hamm, U., Janssen, E., Ruto, Consumer attitudes towards organic versus conventional food with specific quality attributes. 583 -4 (2011) 67-72.

[38] A., Franzen, R., Meyer, Environmental attitudes in cross-national perspective: a multilevel analysis of the issp 1993 and 2000, Eur. Sociol. Rev., 262 (2010) 219-234.

[39] G., Atkinson, I., Bateman, S., Mourato, Recent advances in the valuation of ecosystem services and biodiversity, Oxf. Rev. Econ. Pol., 281 (2012) 22-47.

[40] M., Christie, I., Fazey, R., Cooper, T., Hyde, J. O., Kenter, An evaluation of monetary and non-monetary techniques for assessing the importance of biodiversity and ecosystem services to people in countries with developing economies, Ecol. Econ., 83 (2012) 67-78.

[41] M. H., Alemu, M. R., Morkbak, S. B., Olsen, C. L., Jensen, Attending to the reasons for attribute non-attendance in choice experiments, Environ. Resour. Econ., 54 (2013) 333-359.

[42] D.A., Hensher, , J. M. Rose, W. H. Greene, Inferring Attribute Non-Attendance from Stated choice Data: Implications for Willingness to Pay Estimates and a Warning for Stated Choice Experiment Design. Transportation 392 (2012) 235-245.

[43] E.K., Yiridoe, S., Bonti-Ankomah, R.C., Martin, Comparison of consumer perceptions and preference toward organic versus conventionally produced foods: A review and update of the literature, Renew. Agr. Food Syst., 204 (2005) 193-205. 
[44] M. K., Magnusson, A., Arvola, U.-K. K., Hursti, L., Åberg, P.-O., Sjodén, Choice of organic foods is related to perceived consequences for human health and to environmentally friendly behaviour. Appetite, 402 (2003) 109-117.

[45] C., Durham, The impact of environmental and health motivations on the organic share of produce purchases, Agr. Resource Econ. Rev., 362 (2007) 304-320.

[46] P., Cheattho, Organic agriculture in Cambodia. Phnom Penh, MAFF, 2011, AFACI.

[47] T. B., de Ponti, M. K., van Ittersum, The crop yield gap between organic and conventional agriculture, Agr. Syst., 1080 (2012) 1-9.

[48] S., Wunder, When payments for environmental services will work for conservation, Conserv. Lett. 6 (2013) 230-237. doi: 10.1111/conl.12034.

[49] S., Hess, A., Stathopoulos, D., Campbell, V., O'Neill, S., Caussade, It's not that I don't care, I just don't care very much: confounding between attribute non-attendance and taste heterogeneity, Transportation, 403 (2013) 583-607. 


\section{Appendixes}

Table A.1. Ecosystem services from rice cropping systems

\begin{tabular}{|c|c|c|}
\hline $\begin{array}{l}\text { Rice cropping } \\
\text { systems }\end{array}$ & Practices and Land Use & Ecosystem services \\
\hline Short - term rice & $\begin{array}{l}\text { - Using the existent rice field and deforestation of flooded clear } \\
\text { forest, shrub and grassland on former floating rice field. } \\
\text { - Construction Ring dike, canal and reservoir for irrigation and } \\
\text { drainage or for preventing flood water from flowing into rice fields } \\
\text { - Chemical use (cocktails of pesticides and fertilizer) in all zones } \\
\text { with the same practices } \\
\text { - New breeding variety « High Yield Variety» }\end{array}$ & $\begin{array}{l}\text { Cultural Services: Preserve spiritual practices and beauty of } \\
\text { agricultural landscape, such as rice fields with palm trees. } \\
\text { Provisioning Services: leaves, trunks, fruit and juice from palm } \\
\text { trees for farmers' basic needs } \\
\text { Regulating services: Ensure flood regulation for short-term rice } \\
\text { Provisioning services: resources in daily food consumption }\end{array}$ \\
\hline $\begin{array}{l}\text { Non-organic } \\
\text { Rainy season rice }\end{array}$ & $\begin{array}{l}\text { - Dependence on water regime from flood pulse of TSL with less } \\
\text { than } 30 \mathrm{~cm} \text { height of ring dikes } \\
\text { - Maintenance of existing high lands, spiritual places and palm } \\
\text { trees. Furthermore palm trees are replanted every year next to } \\
\text { village. } \\
\text { - Absence of chemical use or small amounts of fertilizer and } \\
\text { pesticides used if needed } \\
\text { - Use of natural and local varieties (Fragrant and Non-Fragrant rice) } \\
\text { - Use of breeding Medium Term rice fragrant varieties in case of } \\
\text { flood or drought. }\end{array}$ & $\begin{array}{l}\text { Provisioning Services: Leaves, trunks, fruit and juice from } \\
\text { palm trees for farmers' basic needs. } \\
\text { Regulating Services: Respect water regime and alluvial deposit } \\
\text { Regulating Services: Preserve Agro-biodiversity fauna, flora } \\
\text { and amphibians of rice fields. and Water quality } \\
\text { Cultural Services: Preserve natural varieties for the genetic } \\
\text { bank } \\
\text { Cultural Services: Preserve spiritual practices and beauty of } \\
\text { agricultural landscape, such as rice fields with palm trees. }\end{array}$ \\
\hline
\end{tabular}




\begin{tabular}{|c|c|c|}
\hline Organic Rice & $\begin{array}{l}\text { - Use of only existing rice fields, thus absence of new deforestation } \\
\text { of flooded forest, shrub or grassland } \\
\text { - High land and spiritual place, Palm tree are kept. Palm tree are } \\
\text { replanted every year next to village } \\
\text { - Restrain from use of chemicals } \\
\text { - Use new breeding varieties « Fragrant Rice» } \\
\text { - Rice field are protected from flood by ring dikes around } 40 \mathrm{~cm} \\
\text { high to avoid chemical contamination for preserving label }\end{array}$ & $\begin{array}{l}\text { Provisioning Services: Leaf, trunk, fruits and juice for farmers' } \\
\text { basic need. } \\
\text { Regulating Services: Preserve Agro-biodiversity (fauna, flora } \\
\text { and amphibians of rice fields) and Water quality } \\
\text { Regulating Services: Preserve indirectly flooded clear forest } \\
\text { for Habitat and Biodiversity } \\
\text { Cultural Services: Preserve spiritual practices and beauty of } \\
\text { agricultural landscape (Rice field with palm tree). }\end{array}$ \\
\hline Floating Rice & $\begin{array}{l}\text { - Use of only existing rice fields with many trees (flooded clear } \\
\text { forest in zone 3) on it } \\
\text { - Dependence on water regime from flood pulse of TSL } \\
\text { - Existed High land for spiritual place and Palm tree are kept } \\
\text { - Absence of chemical use or use of small amount of fertilizer and } \\
\text { pesticide if needed } \\
\text { - Use natural and local varieties }\end{array}$ & $\begin{array}{l}\text { Provisioning services : firewood, inland fish } \\
\text { Provisioning services: leaves, trunk, fruits and juice for } \\
\text { farmers' basic need. } \\
\text { Provisioning services: Materiel and food from palm trees } \\
\text { Preserve fauna, flora and amphibians of rice fields. No } \\
\text { chemical residue leaching into water. } \\
\text { Regulating services: Flood regulation, Habitat and Biodiversity } \\
\text { Regulating services: Soil formation from deposit ; Respect } \\
\text { water regime and alluvial deposit. } \\
\text { Regulating service: Soil biodiversity and water quality } \\
\text { Preserve natural varieties for genetic bank } \\
\text { Cultural Services: Preserve indirectly spiritual places and } \\
\text { beauty of agricultural landscape (Rice field with palm tree). } \\
\text { Cultural Services: Natural variety conservation }\end{array}$ \\
\hline
\end{tabular}


Table A.2. The attributes and their levels for scenarios' design"

\begin{tabular}{|l|l|l|l|}
\hline Rice Type & Production method & $\begin{array}{l}\text { Targeted ecosystem service } \\
(\mathrm{ES})\end{array}$ & Price/kg \\
\hline 1. Fragrant rice & 1. Certified Organic & $\begin{array}{l}\text { 1. Biodiversity and water } \\
\text { quality of the river }\end{array}$ & $1(3000)$ \\
\hline 2. Normal rice & $\begin{array}{l}\text { 2. Certified Chemical } \\
\text { free }\end{array}$ & $\begin{array}{l}\text { 2. Indirect Flooded forest } \\
\text { conservation }\end{array}$ & $2(4500)$ \\
\hline & $\begin{array}{l}\text { 3. Chemical free but } \\
\text { non certified }\end{array}$ & 3. Natural Variety & $3(6000)$ \\
\hline & 4. Chemical use & 4. No specific ES & 4 (7500) \\
\hline
\end{tabular}

Table A3 Criteria for determining the optimal number of classes (5310 choices from 295 individuals)

\begin{tabular}{|c|c|c|c|}
\hline Number of classes & $\begin{array}{l}\text { Number of } \\
\text { Parameters }\end{array}$ & Log likelihood & $\mathrm{BIC}$ \\
\hline 2 & 21 & -1301 & 2732.09 \\
\hline 3 & 32 & -1261 & 2712.30 \\
\hline 4 & 43 & -1235 & 2735.21 \\
\hline 5 & 54 & -1220 & 2762.16 \\
\hline
\end{tabular}

